- Describes a computerised dental anxiety scale for children called the Smiley Faces Program (SFP).

- The SFP proved to be a reliable and valid measure for children from six years old.

- The program has the added advantage of a computer database with anxiety scores for immediate investigator access.

\title{
Development of a computerised dental anxiety scale for children: validation and reliability
}

\author{
H. Buchanan ${ }^{1}$
}

\begin{abstract}
Objective To provide reliability and validity data on a computerised dental anxiety scale (the Smiley Faces Program or SFP) for children using faces as a response set.

Setting Five schools across Derby, Newcastle-upon-Tyne and Shropshire. Subjects and method The SFP was completed by 464 children (mean age 10.8 years). For validity purposes, 241 children also completed two other children's dental anxiety measures (the Modified Child Dental Anxiety Scale and the Dental Fear Survey). For test-retest purposes 100 of the children completed the SFP two weeks later.

Results The SFP demonstrated good internal consistency ( $\alpha=0.8)$, testretest reliability was good and significant correlations were found between the SFP and the other measures. The children rated the local anaesthetic and drill as the most anxiety-provoking items.

Conclusion This study suggests that the SFP is a valid and reliable measure for assessing children's trait dental anxiety and may help encourage dentists to formally assess dental anxiety.
\end{abstract}

\section{INTRODUCTION}

Child dental anxiety is a common and potentially distressing problem both for the child and the dental practitioner. It is necessary, therefore, to identify and quantify this trait anxiety. Ideally, a scale should be:

1. short in length to maximise response from the children and minimise time for administration;

2. include items which are most relevant to the child dental experience;

3. easily hold the attention of the child; and

4. be simple to score and interpret.

There are many self-report inventories available but none of them encompass all of the criteria outlined above. Possibly the most well known is the Children's Dental Fear Survey Schedule (CDFSS) ${ }^{1}$ which asks children to rate their fear of 15 situations on a five-point scale. These are divided into:

${ }^{1}$ Lecturer in Psychology, University of Derby, Mickleover, Derby, DE3 9GX

Correspondence to: Dr Heather Buchanan

Email:h.buchanan@ibss1.derby.ac.uk

\section{Refereed paper}

Accepted 23 February 05

doi: $10.1038 /$ sj.bdj.4812694

$\odot$ British Dental Journal 2005; 199: 359-362 (a) fear of invasive procedures;

(b) fear of potential victimisation (eg from strangers, being afraid of hospitals in general), and

(c) fear of non-invasive dental procedures.

It has been shown to have good psychometric properties, ${ }^{2}$ though its use in the dental clinic prior to treatment is not appropriate as it includes some irrelevant items such as "having to go to hospital' (most patients are not treated in hospitals). ${ }^{3}$ Furthermore, the scale is 15 items long hence children may lose interest in completing it, which decreases the likelihood of valid responses.

Wong and colleagues ${ }^{3}$ have recently developed the Modified Child Dental Anxiety Scale (MCDAS). This was designed to assess children's concerns about specific dental procedures, and includes items such as extraction and general anaesthesia. It was shown to have concurrent validity with other measures and the test-retest reliability was good. However, there was a considerable amount of missing data in the initial validation, ${ }^{3}$ which may have been related to the length of the questionnaire and the items featured. It could be that the children may not have experienced, and possibly did not understand, procedures such as scraping and polishing.

In summary, although a variety of self-report inventories are available for measuring children's dental anxiety (for more detailed reviews see Aartmann and colleagues ${ }^{2}$ and Newton and Buck $^{4}$ ) there is no scale which is regarded as the 'gold standard'.

\section{The Smiley Faces Program}

The Smiley Faces Program (SFP) is a four item computerised trait dental anxiety scale, using faces as a response set, to assess dental anxiety in children. Faces have been used before when assessing children, ${ }^{5}$ with two recent papers providing evidence that the Facial Image Scale is a valid indicator of child state anxiety in the dental clinic. ${ }^{6,7}$ Hence, faces have been used as a response set within this trait anxiety scale.

The SFP has a number of advantages. First, it is short in length so should maximise the responses by the children and minimise the time for administration. Second, it includes items that are relevant to most children's dental experience (eg having a tooth drilled, sitting in the dental waiting room). Third, the use of computer graphics should help the child engage with the dental anxiety scale. Computer graphics offer interactive animations, which allow participants to control aspects of the visual display in a trial 
and error manner. Some investigators have used computer-based questionnaires to see the effects of computer versus paper-andpencil administration on different types of measures. Children especially rate these as enjoyable, and see the computer version as preferable to pen and paper alternatives. ${ }^{8}$ Third, using a computer to assess anxiety has the advantage of facilitating data collection and standardising assessment. It has the added benefit of minimising the need for an 'expert' administrator, as the instructions are incorporated within the package.

\section{AlM}

The aim of this study was to investigate the reliability and validity of the Smiley Faces Program. Reliability concerns whether an instrument is internally consistent or reproducible. Internal consistency is measured with a single administration of an instrument and assesses how well items within a scale measure a single underlying dimension. Internal consistency is usually assessed using Cronbach's Alpha, which measures the overall correlation between items as well as the level of correlation between items within a scale. ${ }^{9}$ Reproducibility assesses whether an instrument produces the same results on repeated administrations when respondents have not changed. This is assessed by test-retest reliability. The reliability coefficient is normally calculated by correlating instrument scores for the two administrations. Reliability estimates of 0.7 and 0.9 are recommended for instruments that are used in groups and individuals respectively. ${ }^{10}$

Validity is the extent to which an instrument measures what is intended. Concurrent validity is when a measure yields scores that are closely related to scores on a criterion measured at the same time. That is, does the new measure correlate highly with an old measure of the same concept that we judge to be valid?

\section{METHOD \\ Initial development and piloting of the Smiley Faces Program (SFP)}

Using multimedia toolbook, an interactive computerised version of the Facial Image Scale ${ }^{6}$ was developed; this Windows program was entitled Smiley Faces. The pilot program used the same scenarios as the Modified Dental Anxiety Scale ${ }^{11}$ (MDAS). This is a reliable and valid adult anxiety scale ${ }^{11,12}$ which expands and improves on the widely used Corah's Dental Anxiety Scale. ${ }^{13}$ The items are as follows:

1. going to the dentist tomorrow;

2. sitting in the waiting room;

3. about to have a tooth drilled;

4. about to have a scale and polish; and

5. about to have a local anaesthetic injection.

The SFP was piloted using 40 children (mean age $=9.2$ years) from an 'After School' club in Newcastle-upon-Tyne. Consent was given by both parents and children. The instructions and general operation of the program were shown to be sufficiently clear, as the children did not raise any problems or queries. However, there was a problem with the scale and polish item. As the pilot study progressed it became clear that most of the children had not experienced scaling and polishing, and had very little or no concept of what this procedure involved. Although alternative terminology was used (eg 'electric toothbrush') there was still a lack of understanding, thus this item was removed from the program.

\section{Instructions on the program}

At the start of the SFP participant details are requested (surname, forename, age and gender). There then follows questions regarding how the child would feel about:

1. having to have dental treatment the following day;
2. sitting in the waiting room;

3. about to have a tooth drilled; and

4. about to have a local anaesthetic injection.

Question 1 flashes up on the screen for five seconds: 'If you had to go to the dentist tomorrow to get some treatment, how would you feel?' The question leaves the screen and a face in a picture frame with a neutral expression is shown. The child can click on the happy face for the face in the picture frame to become happier and the unhappy face to become sadder. There is a choice of seven faces with face number 4 being 'neutral'. They can control aspects of the display in a trial and error manner. The child finds the appropriate face to match his/her response and clicks 'done'. Questions 2-4 follow in a similar manner.

\section{MAIN STUDY}

\section{Participants}

This study involved a convenience sample of children from four schools in and around Newcastle-upon-Tyne, Derbyshire and Shropshire. Consent was given 'in loco parentis' from the headteachers at the schools and was given verbally from the children. There were 468 children approached to take part in the study and all of these children completed the SFP. In order to collect data for validation purposes, a sub-sample of the children (245) were also asked to complete two paper-based dental anxiety measures. There were missing data for four children, all from the paper dental anxiety measures. An omitted response to a single-item on any of the measures meant that the responses from that participant were eliminated from any analysis which left validation data for 241 children and SFP data for 464 children (mean age $=10.8$ years, $S D=2.9$, range $6-15$ years). All of the children completed the SFP and 100 of these children completed the SFP for a second time (two weeks later) to provide test-retest data. For a full breakdown of gender and age for each part of the study see Table 1 .

\section{Measures}

As well as the SFP, 241 of the children completed the Modified Child Dental Anxiety Scale ${ }^{3}$ (MCDAS) and the Children's Dental Fear Survey Schedule ${ }^{1}$ (DFSS). The MCDAS comprises eight questions, each question asking how relaxed or worried the child is about different dental items (eg having a filling and being put to sleep to have treatment). Children rate themselves on a five-point scale from 1 (relaxed/not worried) to 5 (very worried). Scores can range between 8 and 40. The DFSS comprises 15 items, each item covering a different aspect of the dental situation (eg having to open your mouth; the sight of the dentist drilling). Children rate each item on a five-point scale from 1 (not afraid) to 5 (very afraid). Scores can range between 15 and 75 .

\section{Procedure}

\begin{tabular}{|c|c|c|c|c|c|}
\hline Measure & $\begin{array}{l}\text { Number of } \\
\text { males }\end{array}$ & $\begin{array}{l}\text { Age } \\
\text { [mean, SD] }\end{array}$ & $\begin{array}{l}\text { Number of } \\
\text { females }\end{array}$ & $\begin{array}{l}\text { Age } \\
\text { [mean, SD] }\end{array}$ & $\begin{array}{l}\text { Missing } \\
\text { data }\end{array}$ \\
\hline $\begin{array}{l}\text { Smiley Faces } \\
\text { Program }\end{array}$ & 232 & $10.8(2.9)$ & 232 & $10.9(2.9)$ & 0 \\
\hline $\begin{array}{l}\text { MCDAS } \\
\text { validation } \\
\text { data }\end{array}$ & 120 & $10(2.5)$ & 121 & $10.5(2.4)$ & 3 \\
\hline $\begin{array}{l}\text { CDFSS } \\
\text { validation } \\
\text { data }\end{array}$ & 120 & $10(2.5)$ & 121 & $10.5(2.4)$ & 1 \\
\hline $\begin{array}{l}\text { Smiley Faces } \\
\text { test-retest }\end{array}$ & 52 & $10.5(1.9)$ & 48 & 10.8 (2 yrs) & 0 \\
\hline
\end{tabular}


The children were told that the SFP was a computer package designed to measure how children feel about going to the dentist. At least one investigator and one teacher were present when the children were completing the measures. The items on the paper measures were read out to, and completed, in a class/group. The SFP was completed in smaller groups (due to limited numbers of computers); the instructions and items were read out to younger children and any of the other children who asked for it. Following completion of the SFP, approximately half of the children (241) completed the MCDAS and the DFSS. Moreover, 100 of the children completed the SFP on a second occasion (two weeks later) in order to provide test-retest data

\section{RESULTS}

\section{Reliability}

Estimates of internal consistency as calculated using Cronbach's Alpha demonstrated a high level of reliability for the SFP $(\alpha=$ 0.8). A further analysis was undertaken to examine responses to individual items in more detail. Item-remainder correlations were calculated for each item (Table 2). All correlations were highly significant $(p<0.001)$. Test-retest data from 100 children ( 52 boys and 48 girls) across a two week period showed a strong correlation $(r=0.8, p<0.001)$.

Table 2 Item-remainder correlations for items on the SFP $(n=464)$

\begin{tabular}{ll}
\hline Item & Correlation \\
\hline Dentist tomorrow & 0.6 \\
Waiting room & 0.7 \\
Drill & 0.6 \\
Injection & 0.6
\end{tabular}

\section{Concurrent validity}

The concurrent validity of the SFP was assessed by correlating the scale with two other dental anxiety measures. The SFP was found to significantly correlate with the DFSS $(r=0.6, p<0.01)$ and the MCDAS $(r=0.6, p<0.01)$.

\section{Dental anxiety scores}

The four items included in the SFP were scored from 1 to 7 . Hence, the minimum score possible was 4 and the maximum was 28 (higher score indicates higher anxiety). The mean anxiety score was $18(\mathrm{SD}=4.2)$; the mean score for boys was 18.3 ( $\mathrm{SD}=$ $4.1)$ and $17.8(\mathrm{SD}=4.3)$ for girls. A two-way analysis of variance was employed to test for the effect of gender and age on total dental anxiety scores. There was no effect for gender on dental anxiety $(F(1,453)=1.871, p>0.05)$ though anxiety scores varied significantly across age group $(F(4,453)=93.674, p<0.001)$. There was no interaction between the two factors. Mean values showed a non-linear pattern (see Table 3). A post hoc bonferroni test showed that the 6-7-year-olds were significantly more anxious than the 8-9, 12-13 and 14-15 year-olds and that the 1011-year-olds were significantly more anxious than the 12-13 year-olds.

In order to test whether there were differences in anxiety across the items a repeated-measures ANOVA was employed. There was a

Table 3 Mean (SD) dental anxiety scores across each age group

\begin{tabular}{lll}
\hline Age group & Number & Mean $(\mathrm{SD})$ \\
\hline $6-7$ years & 82 & $19.4(3.9)$ \\
$8-9$ years & 80 & $17.4(3.5)$ \\
$10-11$ years & 70 & $19.2(4.0)$ \\
$12-13$ years & 120 & $17.3(4.1)$ \\
$14-15$ years & 111 & $17.6(4.8)$
\end{tabular}

significant effect of anxiety $(F(2.73,1264.9)=326.3, p<0.001)$. As can be seen from Figure 1, the children rated themselves most anxious when faced with the drill and local anaesthetic injection. The children rated the day before the dental visit as least anxiety-provoking, followed by the waiting room scenario. A post hoc bonferroni test showed that the scores differed significantly across all items except for the local anaesthetic and the drill.

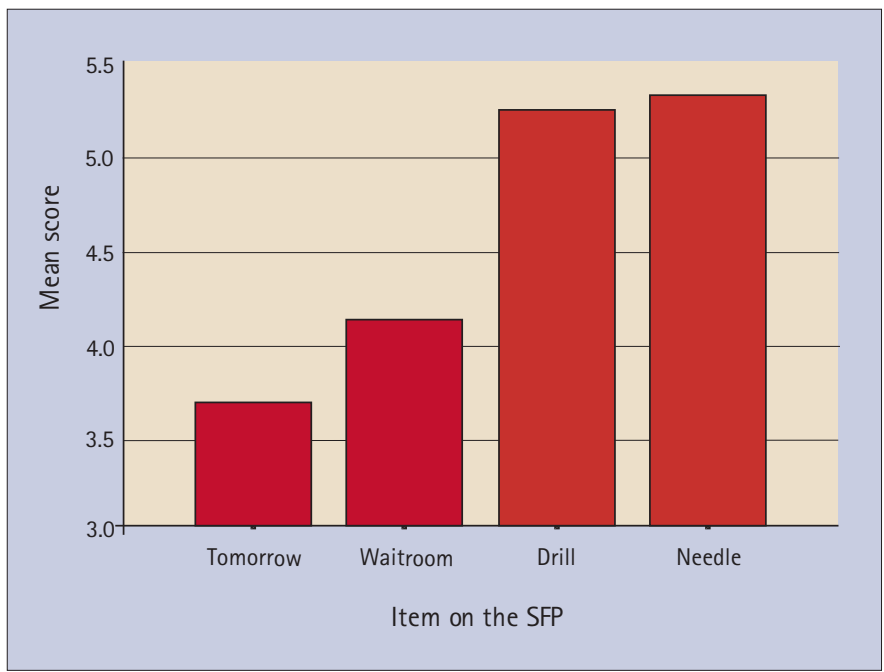

Fig. 1 Mean scores across each item for the SFP

\section{DISCUSSION}

The program was successfully completed by the children; there were no requests for help and they had no problems using the computer. The scale demonstrated good reliability as shown by the high Cronbach's Alpha coefficient and item-remainder correlations. For comparative purposes, the Modified Dental Anxiety Scale (upon which the items were based, excluding the scale and polish item) found similar alpha coefficients with adults. ${ }^{11}$ The stability of the SFP was examined by giving two administrations of the scale to the same participants on two separate occasions. The correlation coefficient was high $(r=0.8)$.

The mean anxiety scores varied across items. This is consistent with Humphris et al.'s ${ }^{11}$ findings using the MDAS with adults. Further analyses revealed that scores varied between all items except the local anaesthetic and drill items. These items also had the highest mean anxiety scores, which supports previous findings from questionnaire studies which have included both of these items. ${ }^{3,14}$ This further supports Humphris et al.'s ${ }^{11}$ assertion that local anaesthetic injections should be included in dental anxiety scales and that high levels of anxiety are associated with it. With the exception of the DFSS and the MCDAS there are few children's anxiety scales which have included the injection. From a clinical perspective it is imperative to cover not only dental anxiety, but also particular items which may provoke anxiety. Indeed, Stouthard et al. ${ }^{15}$ have argued that an accurate assessment of dental anxiety is necessary not only to determine its prevalence, but also to overcome the problems related to individual diagnosis and treatment. The children with very high scores on the injection item may need extra help from dentists to cope with injections. Milgrom et al. ${ }^{16}$ have suggested that patients who are highly anxious about the injection should be questioned to elucidate the nature of their fear, and that this information may suggest how to deal with the problem.

There were no gender differences for overall anxiety scores or for any of the individual items. The literature has produced inconsistent findings as regards gender differences with some studies showing a clear distinction between males and females (girls indicating raised dental anxiety over boys ${ }^{3,17}$ ) and other work showing 
no differences. ${ }^{6,18}$ As past research has not shown a clear consensus (though the literature on adults has produced more clear-cut finding $\mathrm{s}^{19}$ ) the absence of gender differences does not lessen the validity of the SFP.

Dental anxiety varied according to age group in a non-linear fashion. Other researchers have also found this. ${ }^{1,3}$ Wong and colleagues $^{3}$ note that it is difficult to develop a consensus as to how age and anxiety are associated, as the age ranges in studies vary. In the present study, the highest anxiety scores were evident in the youngest children (6-7 years) and the children of 10-11 years. Cuthbert \& Melamed $^{1}$ also found highest fear levels in 6-7 year olds and suggest this may be because this is a time of transition. In addition, Wong and colleagues ${ }^{3}$ found that children of 11 and 15 years were significantly more anxious than the 8-years-olds and suggest that other fears may be experienced at these ages (eg changing schools) which may also influence their dental anxiety scores. This may also reflect the high scores in our study as the 10-11 year olds are around the age where they will be moving to secondary school.

In summary, preliminary results indicate that the SFP is a reliable and valid measure of children's dental anxiety. It also has a number of advantages which may encourage formal assessment of anxiety. First, it is a measure, which routinely takes only a few minutes to complete which is helpful to both the child and investigator. Second, it only includes items relevant to most children's dental experience which helps keep their attention - it is worth noting that there were no missing data for the SFP. Third, the computerisation of the scale helps engage the child thereby increasing the likelihood of maximum response. Fourth, the overall anxiety score can be interpreted quickly and easily. Fifth, it can identify children who are anxious of a particular procedure (eg the local anaesthetic injection). This can be done more easily with the SFP rather than many other children's self-report scales because the former allows comparison of scores between items. This is important in so far as some participants having low total scores for the entire program may produce high scores for one item.

There are, however, limitations of the study and the use of the SFP. First, the study employed a convenience sample; the children were from schools that were approached and agreed to participate in the study. Hence, the generalisation of the results should be considered with caution and further research may consider using a formal sampling technique. Second, there may well be limitations to who can complete the SFP. This study only involved participants who were over six years of age and it is reasonable to suggest that this program would be too complex for children younger than six years to complete. In addition, it may be hypothesised that 'streetwise' older children would be reluctant to complete this program. This was not found in this study, though this may be a function of the convenience sample; further research may identify this as a problem. Furthermore, children with learning difficulties or with English as a second language may struggle with the instructions. However, this would also be the case for established paper and pen measures, thus it may simply indicate further help from an investigator. Third, there could be potential administration issues for administering the SFP in schools. Although most schools have plenty of computers, there will not be one computer per pupil which may slow down data collection [in comparison to pen and paper measures]. However, post-data collection the SFP has the added advantage of having a computer database with anxiety scores for investigators to access straight away.

\section{CONCLUSION}

The Smiley Faces Program has shown good reliability and validity with children from 6-15 years. It also has advantages in that the interactive animation provides children with a straightforward and comprehensible task, while at the same time producing a numerical measure for use by the investigator.

Some of this work was conducted at Newcastle University Dental School with support from a Bradlaw Studentship. I would like to thank Dr Neil S. Coulson, University of Derby, for his helpful comments in the preparation of this paper and Dr Neil Niven, Newcastle University and Sarah Butters for help with some of the data collection.

1. Cuthbert M I, Melamed B G. A screening device: Children at risk for dental fears and management problems. J Dent Child 1982; 49: 432-436.

2. Aartman I H A, Van Everdingen T A, Hoogstraten J, Schuurs A H B. Self-report measurements of dental anxiety and fear in children: A critical assessment. J Dent Child 1998; 65: 252-258.

3. Wong H M, Humphris G M, Lee G TR. Preliminary validation and reliability of the modified child dental anxiety scale. Psychological Reports 1998; 83: 1179-1186.

4. Newton J T, Buck D J. Anxiety and pain measures in dentistry: A guide to their quality and application. J Amer Dent Ass 2000; 131: 1449-1156.

5. Williams J M G, Murray J J, Lund C A, Harkiss B, De Franco A. Anxiety in the child dental clinic. J Child Psychol Psychi 1985; 26: 305-310.

6. Buchanan $\mathrm{H}$, Niven $\mathrm{N}$. Validation of a facial image scale to assess child dental anxiety. Int J Paed Dent 2002; 12: 47-52.

7. Buchanan H, Niven N. Further evidence for the validity of the Facial Image Scale. Int Paed Dent2003: 13: 368-369.

8. Nelson L J, Cooper J. Gender differences in children's reactions to success and failure with computers. Computers in Human Behaviour 1997; 13: 247-267.

9. Cronbach $\mathrm{L} J$. Coefficient alpha and the internal structure of tests. Psychometrika 1951; 16: 297-334.

10. Fitzpatrick R, Davey C, Buxton M J, Jones D R. Evaluating patient-based outcome measures for use in clinical trials. Health Technology Assessment 1998; 2

11. Humphris G M, Morrison T, Lindsay S J E. The Modified Dental Anxiety Scale: validation and United Kingdom norms. Community Dental Health 1995; 12: 143 150

12. Humphris G M, Freeman $R$, Campbell J, Tuutti $H$, D'Souza V. Further evidence for the reliability and validity of the Modified Dental Anxiety Scale. Int Dent J 2000; 50: 143 150

13. Corah N L. Development of a dental anxiety scale. J Dent Res 1969; 48: 596

14. Klingberg G, Berggren U, Noren J G. Dental fear in an urban Swedish child population: prevalence and concomitant factors. Comm Dent Health 1994; 11: 208 214

15. Stouthard M, Hoogstraaten J. Ratings of fear associated with twelve dental situations. J Den Res 1987; 66: 1175-1178.

16. Milgrom P, Coldwell SE, Getz T, Weinstein P, Ramsay D S. Four dimensions of fear of dental injections. J Amer Dent Ass 1997 128: 757-762.

17. Raadal M, Milgrom $P$, Weinstein $L$, Mancl $L$, Cauce $A$ M. The prevalence of dental anxiety in children from low-income families and its relationship to personality traits. J Dent Res 1995; 74: 1439-1443.

18. Corkey B, Freeman R. Predictors of dental anxiety in six-year old children: findings from a pilot study. J Dent Child 1994; 61: 267-271.

19. Liddell A, Locker D. Gender and age differences in attitudes to dental pain and denta control. Comm Dent Oral Epid 1997; 25: 314-318. 